\title{
Hydrodynamic mechanism of syringomyelia: its relationship to myelocele
}

\author{
W. JAMES GARDNER ${ }^{1}$ \\ From Cleveland, Ohio, U.S.A.
}

'Syringomyelia found in an adult is a rest of a congenital hydromyelia ... which cuts itself off from the central canal posteriorly.' (Leyden, 1876).

The thesis of this present communication is that syringomyelia originates in embryonal life as a result of overdistension of the neural tube. In its simple form the syrinx consists merely of a dilated central canal of the cord. More commonly, it is a ramifying diverticulum originating in the central canal or floor of the fourth ventricle and dissecting along a path of least resistance paralleling fibre tracts. In either event the syrinx is not 'cut off' but during life is kept distended with ventricular fluid that enters it with each pulse beat because the outlets of the fourth ventricle did not develop properly.

The above concept evolved quite serendipitously because of an inadequacy in radiological equipment at the Cleveland Clinic Hospital in the 1930s. In those days pneumoencephalography could be performed quite effectively in a room of the surgical pavilion equipped to make films in the upright posture. For ventriculography requiring the horizontal posture, it was necessary to move the patient some distance from the surgical pavilion where resuscitative measures were inadequate. For these reasons, in cases of suspected brain tumour without papilloedema, pneumoencephalography was preferred to ventriculography and was employed even in posterior fossa cases. Because of this practice the pneumoencephalographic picture of the cerebellar tumour gradually unfolded (Gardner and Nosik, 1942). It was found to consist of an absence of air in the ventricles, a midline position of the supracallosal sulcus, and a filling defect in the cisterna magna outlining a cerebellar hernia. In operating upon such patients, the anticipated tumour sometimes proved to be a congenital hernia of the hindbrain resembling that seen in the infant with myelocele, and below this hernia was a cystic spinal cord. As a result of such experiences the light gradually dawned that this was symptomatic syringo'Present address: 930 Hanna Building, Cleveland, Ohio. bulbia with asymptomatic syringomyelia. Then came a patient with classic symptoms of syringomyelia without posterior fossa signs. Pneumoencephalography revealed the same picture and operation again disclosed a congenital hernia of the hindbrain and a cystic cord distended with clear, colourless cerebrospinal fluid. Separation of the impacted cerebellar tonsils allowed the ventricular fluid to pulsate freely through the previously impacted foramen of Magendie. After this decompression, the patient's symptoms improved.

A case of particular significance to the present discussion was encountered in October 1955 (Gardner, Abdullah, and McCormack, 1957). This patient had classic symptoms of syringomyelia and syringobulbia. Instead of the anticipated hernia of the hindbrain, operation revealed a dilated fourth ventricle enclosed by a membrane representing an unperforated rhombic roof. This so-called DandyWalker malformation is a recognized cause of congenital hydrocephalus, that, along with hydromyelia, has been reported in infants with myelocele (Benda, 1952; Dandy, 1921). This further evidence of a relationship between adult syringomyelia and infantile myelocele led to a careful search for indication of failure of perforation of the rhombic roof in cases of congenital hernia of the hindbrain. In this condition also, a similar membrane frequently was found enclosing the foramens.

During the past 25 years the cerebellum has been exposed in 74 patients with syringomyelia. In each case there was a congenital deformity of the hindbrain resembling that found in the infant with myelocele. In many instances the foramen of Magendie was closed by a membrane. Fluid aspirated from the distended syrinx always was clear and colourless suggesting an origin in the choroid plexus. When dye or radiographic medium was injected into the ventricles it passed into the syrinx. These observations indicate that the syrinx communicates with the fourth ventricle and is distended with fluid entering it because of failure of the foramens to open adequately in prenatal life. A brief review of the embryological 
development of the cerebrospinal fluid spaces is pertinent to the present discussion.

\section{EMBRYOLOGY}

The neural tube is a single cavity consisting of the ventricles and central canal of the cord. In 1917 Weed showed that by the sixth week of embryonal life this tube is distended with fluid that has begun to filter through attenuating areas in the membranous roof of the primitive fourth ventricle. By the eighth week the pressure of this filtrate has dissected open the entire subarachnoid space. During this critical period the filtration pressure causes a further dilatation of the primitive ventricles and central canal (Fig. 1). This embryonal hydrocephalus and hydromyelia, better termed 'hydrocephalomyelia' since it is a single cavity, becomes compensated long before attenuating areas in the roof of the fourth ventricle perforate to form the foramens. Weed postulated that if attenuation had not rendered the rhombic roof adequately permeable during this critical sixth to eighth week period, a sufficient quantity of fluid could not escape from within the distended lumen (obstructive hydrocephalus) to complete the dissection of the subarachnoid spaces. Then communicating hydrocephalus would prevail regardless of whether the foramens subsequently opened. Thus, almost a half century ago, Weed offered a logical explanation as to why congenital hydrocephalus is so common, and why it may be either obstructive or communicating, or more commonly a combination of both; also, although he failed to mention it, why hydromyelia so often is associated with con- genital hydrocephalus (Cameron, 1957). That Weed's $Z$ views are not more widely accepted today is a striking example of the time lag that so frequently intervenes between laboratory demonstration and clinical acceptance.

In syringomyelia of adult life as in myelocele of $\stackrel{ }{\top}$ infancy one may find the combination of hydrocephalus, hydromyelia, and an unperforated rhombic roof (Gardner, 1959a). Both disorders, therefore, $\vec{z}$ appear to represent the postnatal persistence of conditions that are physiological in the embryo. The unperforated rhombic roof is usually concealed $\bar{c}$ in the impaction of a congenital hernia of the hind- 흠 brain (Fig. 2) but occasionally it is quite obvious $\frac{}{5}$ in an expanded Dandy-Walker malformation $ه$ (Gardner, 1959b).

Chiari, in 1891, attributed congenital hernia of the hindbrain to 'hydrocephalus of the cerebrum'. His type 1 (Fig. 3), consisting chiefly of a herniation $\overrightarrow{\vec{H}}$ of the tonsils, he described in an adult with hydro- $\omega$ cephalus and hydromyelia; his more severe type 2 , since then unjustly labelled (Daniel and Strich, 1958; 0 Greenfield, Blackwood, McMenemey, Meyer, and i Norman, 1958) the 'Arnold'-Chiari malformation $\omega$ he described in an infant with hydrocephaluo is hydromyelia, and myelocele. In his extraordinarip complete descriptions (Chiari, 1895), like most sule sequent authors, he failed to note that in many cases. membranes enclosing the foramens of the fourth ventricle bear mute evidence of the fact that the $\overparen{D}$ rhombic roof has failed to perforate (Gardnes. $\vec{\bullet}$ $1959 \mathrm{~b})$. This oversight is due to the fact that these of membranes are concealed in the impacted hernia. That they frequently remain intact is rather surpris-

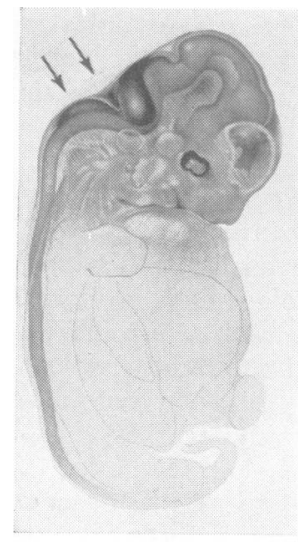

$a$

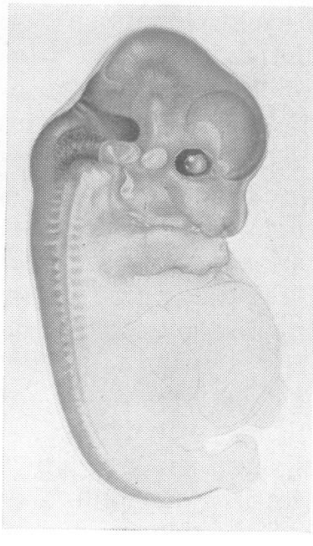

$b$

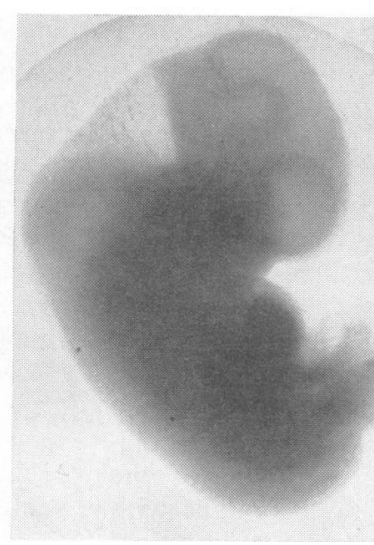

c

FIG. 1. The physiological hydrocephalus and hydromyelia of embryonal life.

a. An $18 \mathrm{~mm}$. pig embryo corresponding to the sixth week in the human, with the cerebrospinat fluid spaces outlined by precipitated crystals of Prussian blue. The ventricular fluid is just beginning to push through two permeable areas in the rhombic roof. Arrows indicate $\overline{t h e}$ area membranacea superior and inferior.

b. A $26 \mathrm{~mm}$. pig embryo corresponding to the eighth week in the human reduced to the same sizen as $a$, to depict the increasing distension of the neural tube. The subarachnoid spaces have expanded and precipitated crystals of Prussian blue were found in the venous dural sinuses.

c. A six-week human embryo photographed by transillumination in its amniotic sac. The lighter areas correspond to the darker areas in $a . \bar{\sigma}$ 

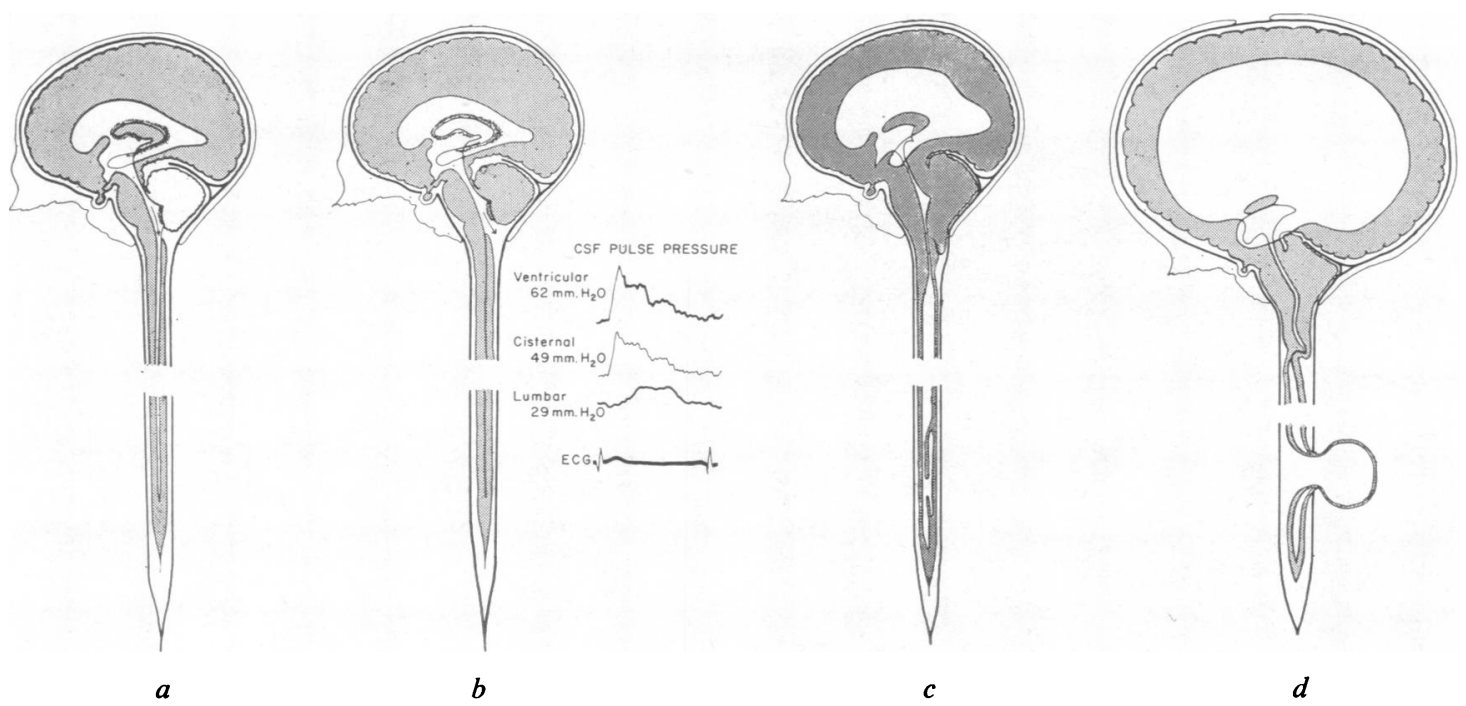

FIG. 2a. Diagram showing the outline of the embryonal neural tube superimposed upon the configuration of the mature central nervous system. The outlet of the fourth ventricle is bridged by a permeable membrane that funnels the pulsations of the ventricular fluid into the central canal of the cord (arrow). Despite its vulnerable position, persistence of this membrane (area membranacea inferior of Weed) may be demonstrated not only in every Dandy-Walker malformation but also in many Arnold-Chiari malformations.

b. After the foramens open, the pulsations escape freely into the subarachnoid space (arrow) onto the outer surface of the spinal cord. As a result of this bypass the central canal is compressed and becomes a vestigial structure. The ventricular fluid pulse pressure is progressively damped as it descends in the expansible dural sac. The pulse pressure recordings are from Bering (1955).

c. Diagram of the neural tube in syringomyelia. The ventricles frequently are enlarged but the intracranial pressure is normal (compensated hydrocephalus). The foramens of the fourth ventricle are compressed by impaction in a congenital hindbrain hernia. The central canal at the level of the hernia is usually patent but cannot dilate because of the impaction. Below the impaction the central canal is enormously dilated with loss of its ependymal lining except for small areas on the wall adjacent to the anterior commissure. Dilatation is greatest in the cervical region where the transmitted ventricular fluid pulse pressure is widest. A false diverticulum of the neural tube, as shown below the cut, may develop at any level to form a 'true syrinx' that parallels the central canal and is entirely lacking in ependyma. It may originate from the floor of the fourth ventricle (syringobulbia) and by its downward extension, collapse the central canal.

d. Diagram of the neural tube in myelocele. The severe hindbrain hernia has telescoped the cervico-medullary junction and closed the communication between fourth ventricle and dilated central canal. The ependyma lining the canal is much better preserved than in the adult form. The intracranial pressure is increased, the ventricles are greatly dilated (uncompensated hydrocephalus), and in certain cases their ependymal lining may be lacking. False diverticuli of the dilated ventricles or central canal may be present.

ing since their position renders them liable to rupture as the hydrocephalic head is squeezed in its passage through the birth canal. Chiari's demonstration of the presence of hydromyelia and hydrocephalus with both this adult type 1 and his infantile type 2 herniations supports the present theory that syringomyelia in adults is the result of a mild degree of overdistension of the neural tube compensated in utero, while the hydrocephalus and hydromyelia that accompany myelocele result from a severe degree that failed to become compensated (Gardner, 1961). Chiari, however, did not attribute the hindbrain hernia to extrusion resulting from growth of the hindbrain in a posterior fossa too small to accommodate it. Apparently he failed to recognize the abnormally low position of the transverse sinus (Cameron, 1957; Daniel and Strich, 1958) that had seriously reduced the size of the posterior fossa.

Padget (1957) has shown that the anlage of the transverse sinus and tentorium arises far anteriorly and is pushed posteriorly by the expanding forebrain (Fig. 4). This excursion is almost completed by the twelfth week, at which stage the brain still is little more than a thin-walled bag of water containing a relatively enormous choroid plexus. In view of this fact, it follows that the excursion of the primitive transverse sinus is the result of fluid expansion of the forebrain rather than the growth of solid tissue as was suggested by Barry, Patten, and Stewart (1957). Furthermore, since the pressure of fluid in a closed 


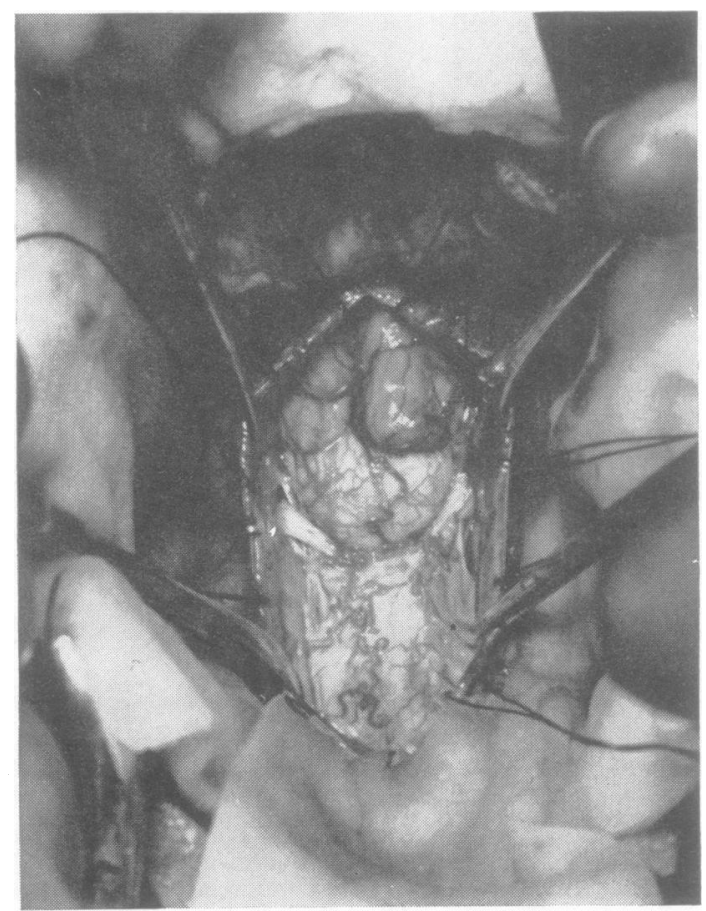

FIG. 3. Surgical exposure in a patient with syringomyelia. The cerebellar tonsils are protruding through the foramen magnum as in Chiari's type 1 malformation. The second cervical nerve roots slant upward and the cervico-medullary junction bulges posteriorly as in Chiari's type 2 malformation. Below this the cystic cord, tethered laterally by the dentate ligaments, has collapsed in the antero-posterior plane as a result of the pre-operative encephalogram (see Fig. 6).
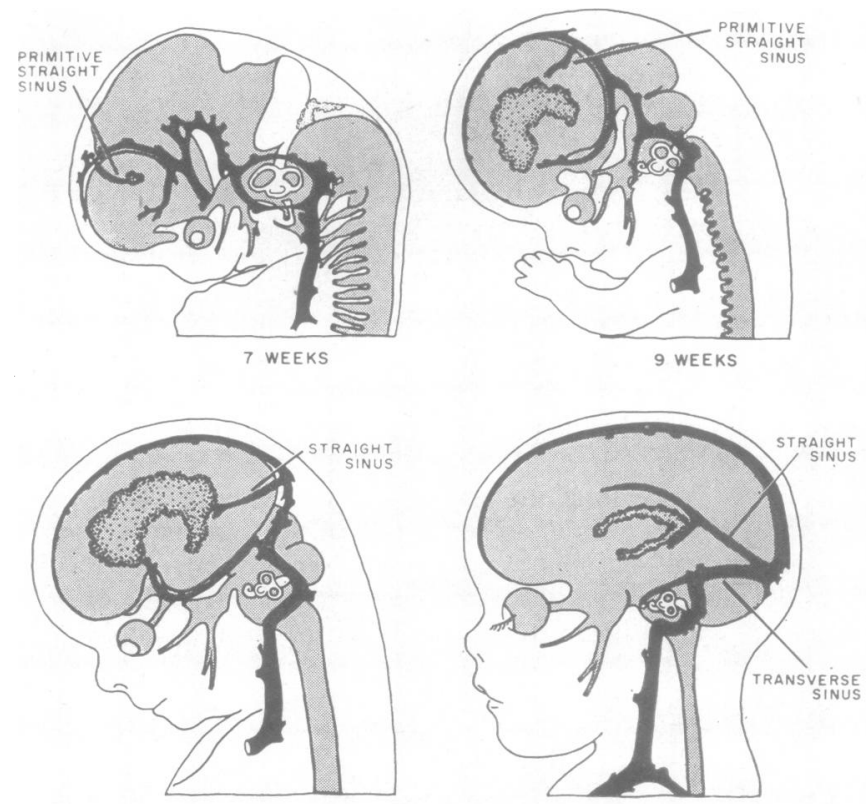

FIG. 4. The transverse sinus with its attached tentorium originates far forward and is pushed posteriorly by the expanding forebrain. If it is pushed too far, the developing posterior fossa will be too small, as in the Chiari malformation. If it is not pushed far enough, this fossa will be too large, as in the Dandy-Walker malformation. The migration of the primitive straight sinus rather than the transverse sinus is shown, since the former is identifiable at an earlier stage than is the latter. The relatively large size of the choroid plexus indicates its functional significance (redrawn from Padget, 1957).

$$
\text { INFANT }
$$


system is exerted equally in all directions, this expansion of the forebrain at the expense of the hindbrain can be explained only on the basis of greater yielding qualities inherent in the coverings of the forebrain. In other words, the migration of the primitive transverse sinus is the result of hydrodynamic forces in which the expansion of the forebrain competes with that of the hindbrain.

If, due to inadequate permeability of the rhombic roof, the physiological hydrocephalus of the forebrain attains a pathological degree, it will push the movable partition too far caudally. This will result in a posterior fossa too small to accommodate the later growth of the hindbrain so that its posterior portion will be extruded through the foramen magnum. Chiari's hypothesis that hernia of the hindbrain is due to "hydrocephalus of the cerebrum', therefore, still will apply. If the size of the posterior fossa is severely reduced by this process, the cerebellar portion of the resulting hernia will consist of the earlier developing vermis (Chiari's type 2); if its size is reduced to a lesser degree, the cerebellar hernia will consist of the later developing tonsils (Chiari's type 1). In the severe herniations the dilated central canal is kinked and cut off from the fourth ventricle by the telescoping of the upper cervical cord. The accompanying operative photographs illustrate that gradations exist between Chiari's types 1 and 2.

Contrariwise, if the coverings of the hindbrain of the hydrocephalic embryo are relatively more yielding than those of the forebrain, the resulting overexpansion in the primitive hindbrain area will interfere with the posterior migration of the transverse sinus and result in an abnormally large posterior fossa. The developing hindbrain then will be inadequate to fill this large fossa and the remaining space will be occupied by a dilated fourth ventricle constituting the Dandy-Walker malformation. Thus, inadequate permeability of the rhombic roof, as proposed by Weed (1917), will explain not only congenital hydrocephalus with its hydromyelia but also the accompanying hindbrain malformations of Chiari and of Dandy and Walker (Gardner, 1964). All these features are encountered in the adult with syringomyelia as well as in the infant with myelocele (Gardner, 1959a).

Clinicians and pathologists recognize that obstruction of the ventricular system at any level results in uniform dilatation of that part of the system above the obstruction. This observation, quite true in cases developing in postnatal life, led to the prompt acceptance of foramenal obstruction as the cause of the dilated fourth ventricle in the Dandy-Walker malformation. By the same token, it has seriously delayed our recognition that this foramenal obstruc- tion is the cause of the compressed fourth ventricle in the Chiari malformation.

\section{THE HYDRODYNAMIC THEORY}

Every living membrane, of necessity, is permeable to fluid. The difference between a perforated and a permeable membrane is merely the size and number of its holes (Gardner, McCormack, and Dohn, 1960). In the rhombic roof such holes, whether macroscopic or ultramicroscopic, may be competent to allow passage of ventricular fluid at the same rate as it is formed, but incompetent to allow passage of the sudden spurt imparted to it by each pulse beat of the choroid plexus. This may be compared to a window screen readily permeable to a breeze but which bulges in response to a sudden gust. In syringomyelia the intracranial pressure is normal although the foramens of the fourth ventricle may appear to be 'sealed' by such membranes. This fact, together with observations during surgery, indicate that it is not an increase in mean pressure of the ventricular fluid which drives it down into the spinal cord, but rather the gentle, oft repeated water hammer effect of its pulse pressure. In other words, although the foramens of the fourth ventricle are competent to equalize the mean pressures within and without the lumen, they may not be competent to equalize the pulse pressures. According to this theory the formation of a syrinx is a process of hydrodissection comparable to that which is responsible for developing the subarachnoid space in the embryo. It differs in that the hydrodynamic force is purely pulsatile and is misdirected. Apropos at this point is Greenfield's (1958) description of the syrinx: 'Where there is a recent extension ... the appearances suggest tearing of the tissues and transudation of serous fluid into them.'

Bering (1962) pointed out that the beating of the choroid plexus transmits to the ventricular fluid a compression wave, absorbed in part by the spurting of fluid from the fourth ventricle into the distensible spinal subarachnoid space. He found symmetric hydrocephalus did not develop if the choroid plexus was removed from one ventricle, and the animal was made hydrocephalic by the injection of kaolin into the cisterna magna. In the ventricle lacking a choroid plexus the pulse wave was feeble. This ventricle remained small while the other dilated, even though the foramens of Monro were patent. If unilateral choroid plexectomy was done in animals with established hydrocephalus, that ventricle shrank while the opposite one continued to enlarge by virtue of the force of the compression wave generated by its choroid plexus. In this fashion, Bering demonstrated that dilatation of the mature neural tube is a 

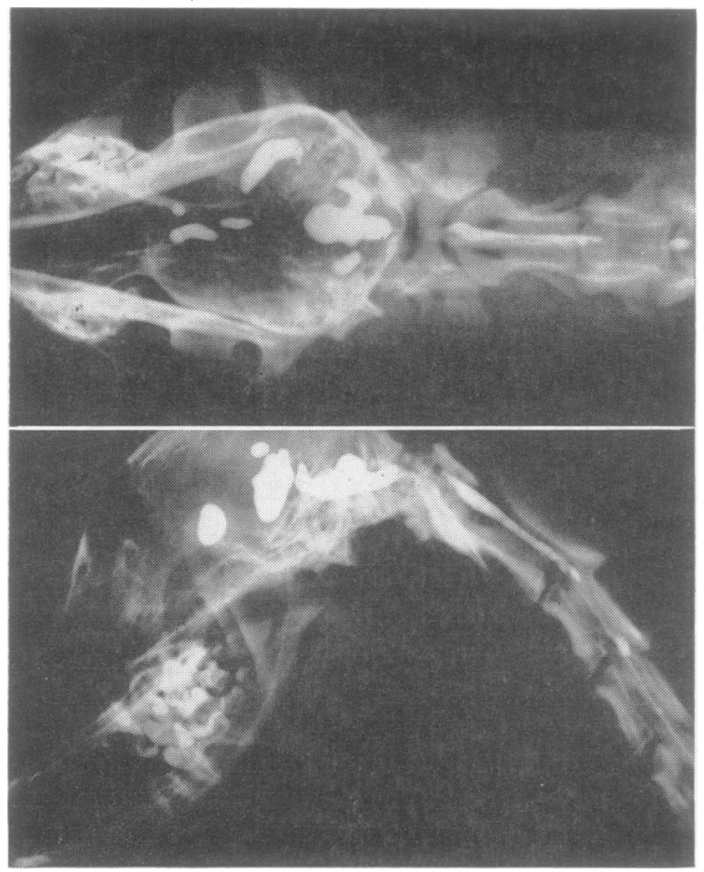

FIG. 5. In experimental hydrocephalus, injection of Pantopaque into the obstructed fourth ventricle shows that it communicates with a dilated central canal. This constitutes acquired hydrocephalomyelia. (By courtesy of McLaurin et al., 1954; with permission of the publisher).
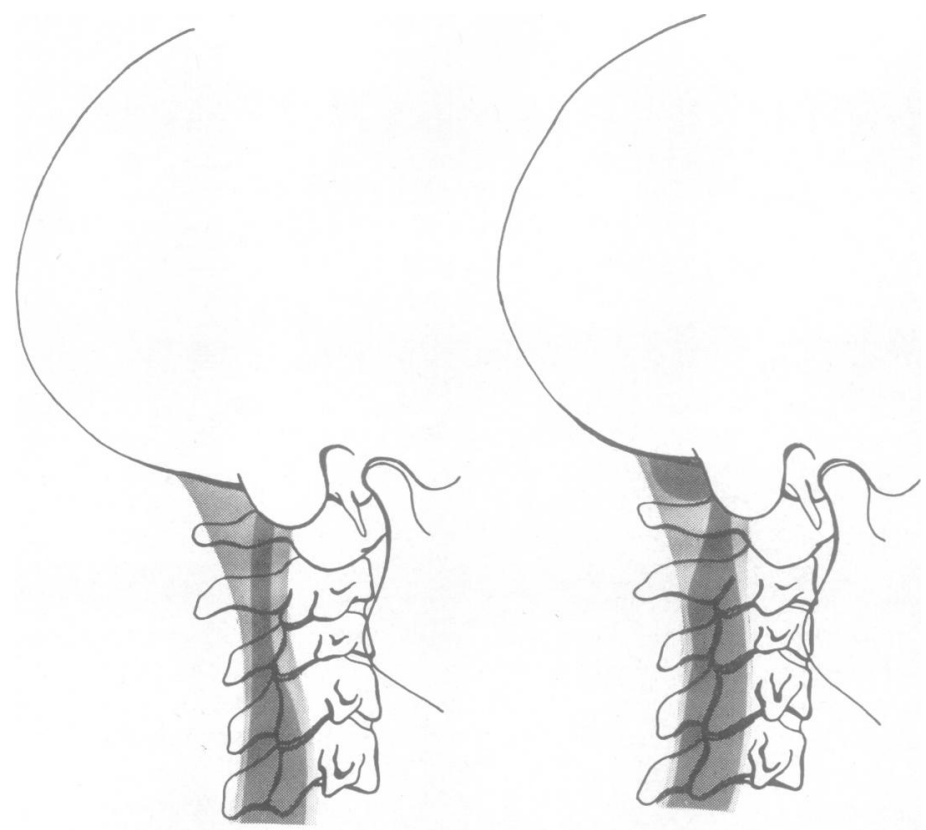

FIG. 6. A pneumoencephalogram with the patient in the sitting position is reproduced diagrammatically. Air has failed to enter the ventricles.

a. A film made immediately after the complete exchange disclosed herniated tonsils outlined by air in the cisterna magna and a distended cord below.

b. A later film showed that the removal of the subarachnoid fluid had allowed the fluid in the syrinx to gravitate downward and to filter through its attenuated walls so that the upper portion collapsed. This drainage of fluid from the syrinx created a negative pressure within the ventricles which sucked the cerebellar hernia up through the foramen magnum. function of the ventricular fluid pulse pressure rather

Previous experimental studies by McLaurin, Bailey, Schurr, and Ingraham (1954) had shown that dilatation affecting the entire neural tube, that is, the ral canal of the cord as well as the cerebral the ventricles of their animals, it did not in from the foramens into the subarachnoid space but passed from the fourth ventricle into a dilated central canal. Thus, hydromyelia developed when the oramens of the fourth ventricle were rendered inhydrodynamic theory of the mechanism of syringomyelia (Fig. 5).

\section{RADIOLOGICAL AND SURGICAL FINDINGS}

The diagnosis of syringomyelia may be confirmed Eugenio, Hughes, and Gardner, 1958) the pneumoencephalogram characteristically will disclose \& filling defect in the cisterna magna as well as failurs of air to enter the ventricles. Below the filling defect the films may show a collapse of the cystic cord (Fig 0 ). Collapse occurs because withdrawal of the sup? the fluid within the syrinx to gravitate downware and to filter through its attenuated walls so that the 
only in the antero-posterior direction because the distended cord is anchored laterally by the dentate ligaments. Pneumoencephalography was done preoperatively in 46 of 74 cases that constitute the basis of this report. The films disclosed no air in the ventricles in 24 cases. In 22 cases some air gained entrance to the lateral ventricles indicating that they were dilated in 14 and normal in eight. These radiological findings constitute further evidence of incompetence of the foramens of the fourth ventricle.

Proper surgical treatment of syringomyelia consists not in incising the syrinx but in dissecting open the foramen of Magendie to permit the escape of the confined ventricular fluid pulsations previously funneled into the syrinx. These pulsations then will be shunted past the central canal into the cisterna magna, restoring the dynamics of the cerebrospinal fluid to normal. Through a midline incision and with the patient in the sitting position, the foramen magnum is enlarged posteriorly, the lamina of the upper cervical vertebrae are removed, and the dura is opened widely. The cerebellar tonsils will be found elongated and herniated into the foramen magnum so that the passageway between them and the medulla is squeezed shut by the impaction (Fig. 7). Furthermore, the surgeon will observe that this impaction is accentuated momentarily by a downward excursion of the tonsils that occurs with each pulse systole. The cerebellar hernia in syringomyelia not only interferes with the escape of the ventricular fluid pulse wave from the lumen of the neural tube, but the impaction of this hernia also creates a mild subarachnoid block at the foramen magnum. These two hydrodynamic factors serve to exaggerate the ventricular fluid pulse wave and to funnel it toward the take-off of the central canal beneath the obex. The surgeon may relieve the subarachnoid block by enlarging the foramen magnum and the ventricular block by dissecting open the passageway between the cerebellar tonsils and the medulla.

In many cases the foramen of Magendie will be bridged by a membrane representing an unperforated rhombic roof (Fig. 8). Incision of this membrane will disclose the floor of the fourth ventricle, and a funnel-shaped upper end of the central canal then may be demonstrated beneath the obex (Fig. 7b). Frequently, there is an unusually deep median raphe leading into it. This funnel-shaped entrance should be plugged with a bit of muscle or a wisp of cotton in order to close off the central canal from the fourth ventricle. This plugging procedure, initiated in 1957 , has been accomplished in each of the last 33 cases. A syrinx opening on to the floor of the fourth ventricle was not described in any of the operative notes. However, such a diverticulum could readily be overlooked, particularly if it originated in a deep median raphe, which in reality constitutes an extension of the central canal. In concluding the operation it is essential that the dura be left open, for if it is closed the foramen of Magendie once more will be squeezed shut and the partial subarachnoid obstruction at the foramen magnum re-established. In recent cases, the insertion of a patch of plastic dural substitute has permitted a relaxed closure of the dura which does not re-impact the hindbrain hernia. This important step improves convalescence by preventing access to the subarachnoid space of proteinladen interstitial fluid escaping from the raw surface of the nuchal muscles. Such access is indicated by spinal fluid protein levels up to $300 \mathrm{mg}$. per $100 \mathrm{ml}$. persisting in some cases for weeks after operation. The presence of excessive amounts of protein has been shown to interfere with the absorption of cerebrospinal fluid (Gardner, Spitler, and Whitten, 1954).

It is not only unnecessary but it may be inadvisable to carry the laminectomy low enough to expose the syrinx, for the reason that extensive laminectomy sometimes has been followed by a severe flexion deformity of the cervical spine. In this series of 74 cases, however, the syrinx was disclosed in 62 , thus confirming the diagnosis. In most of these 62 cases the correct diagnosis was indicated pre-operatively by the clinical findings and/or the pneumoencephalographic picture. In the 12 remaining cases, although the syrinx was not seen, the diagnosis was arrived at because of a characteristic dissociated sensory loss, a typical pneumoencephalographic picture, or a combination of both. In some instances, indigo carmine, previously injected into a lateral ventricle, was aspirated from the syrinx at operation. In one patient indigo carmine was injected into the exposed syrinx, after which manual compression of the cystic cord caused the dye to appear on the floor of the fourth ventricle. In one early case in which a high cervical cord tumour was suspected a cisternal myelogram was attempted. The films showed that the lipiodol had been injected into a caudally displaced fourth ventricle. Twenty-four hours later, most of the lipiodol remained in the fourth ventricle, but a drop of it was observed in the centre of the spinal canal at the level of the first thoracic vertebra, presumably in the syrinx. In a later case, Pantopaque injected into a lateral ventricle also did not escape from the fourth ventricle into the subarachnoid space but gradually trickled in a fine stream through the upper end of the central canal into the syrinx (Fig. 9).

Because the syrinx is distended during life the surgeon has an opportunity, seldom afforded the pathologist, to aspirate fluid from it. In each of 26 

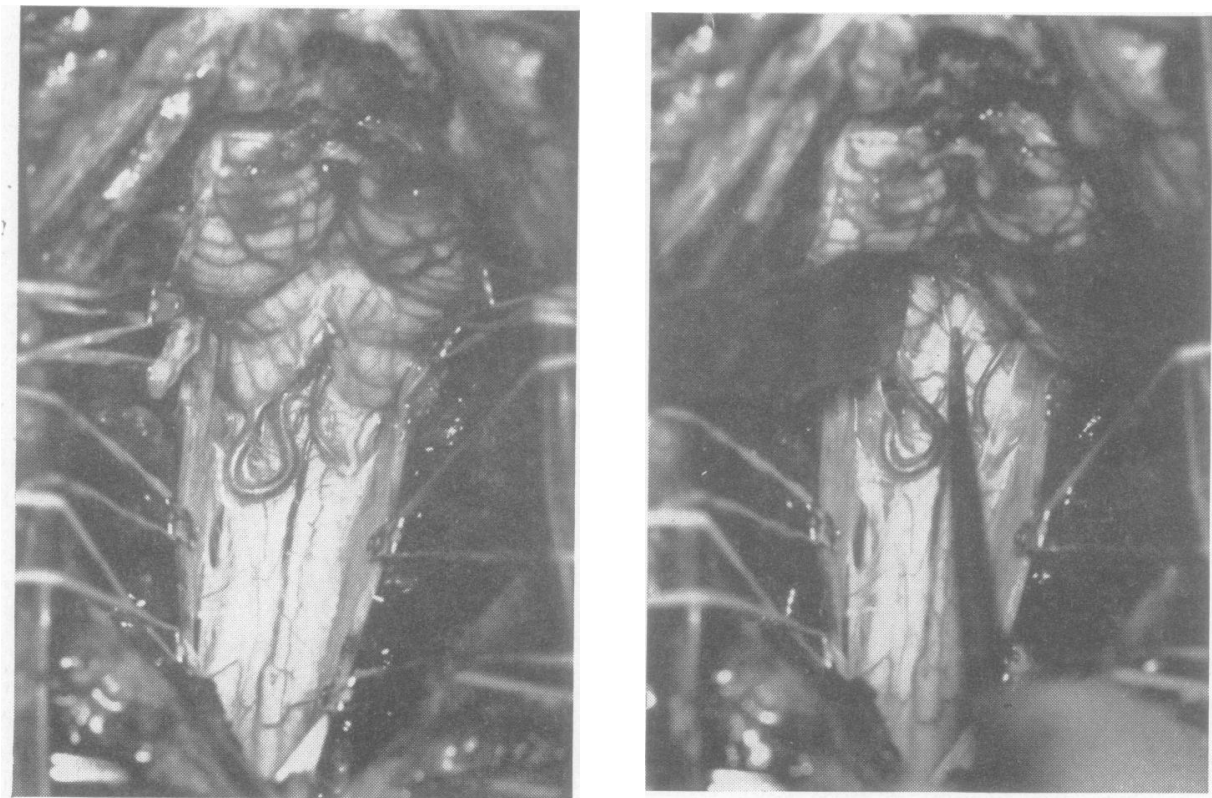

$b$

FIG. 7. Surgical exposure in a patient with syringomyelia.

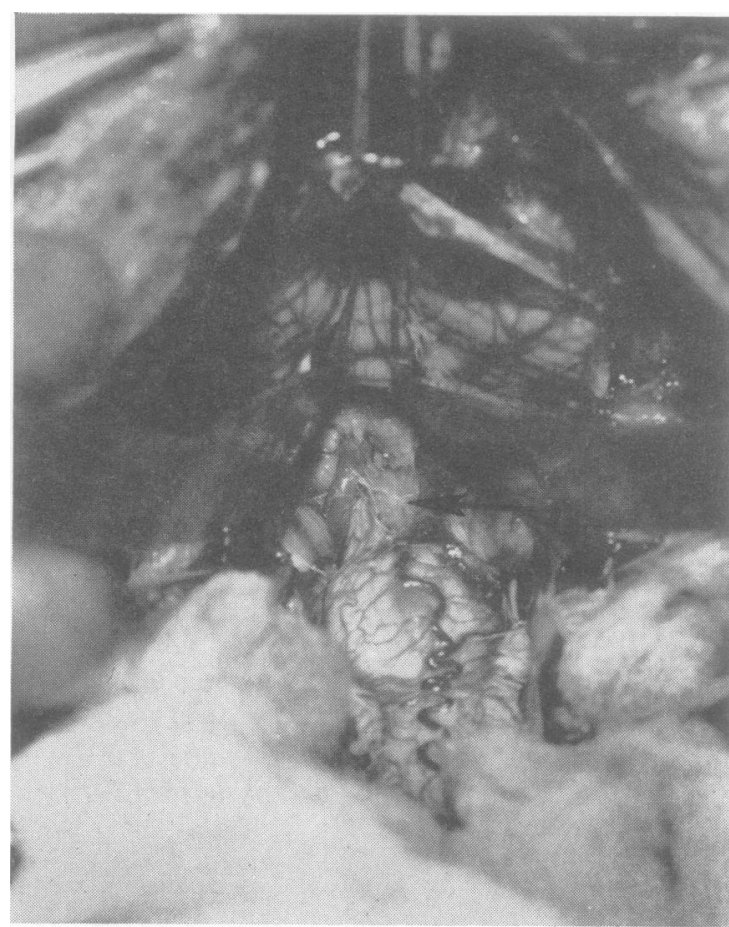

FIG. 8 .
FIG. 7a. Impaction of the cerebellar hernia has squeezed shut the foramen of Magendie and has caused a partiaß subarachnoid block at the foramen magnum. The posteriag inferior cerebellar arteries are redundant.

FIG. 7b. The cerebellar tonsils have been retracted and $\frac{\overrightarrow{2}}{\vec{t}} \mathrm{~S}$ nerve hook introduced to demonstrate the entrance to the central canal. The operative results are improved if this funnel-shaped communication is closed off by impacting in it a tiny muscle plug or wisp of cotton.

FIG. 8. Surgical exposure in a patient with syringomyelia. Retraction of the herniated cerebellar tonsils in this case discloses a membrane (arrow) entirely enclosing the foramen of Magendie. Its attachments indicate that it represents a persistent portion of the embryonic rhombic roof. 


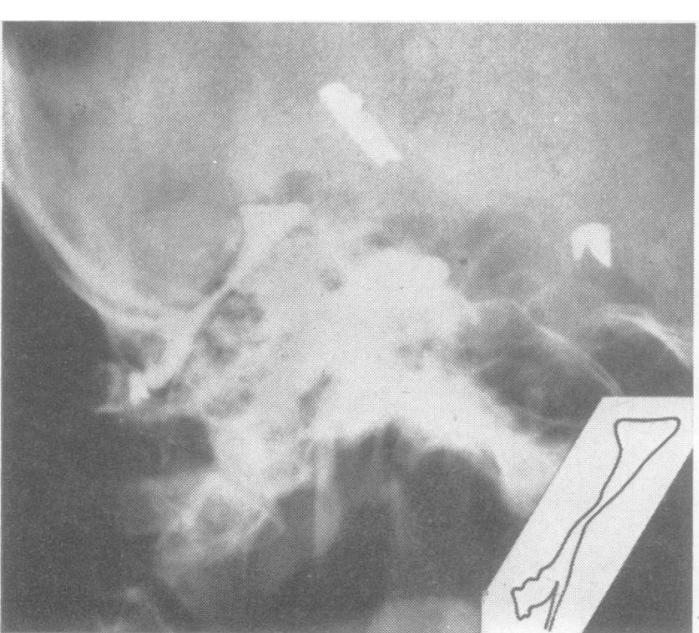

FIG. 9. Pantopaque ventriculogram in a patient with syringomyelia, made with the head erect. The medium has not escaped into the subarachnoid space but is held in the fourth ventricle and in a caudal diverticulum between the cerebellar tonsils. At operation this diverticulum was found to be caused by dense pia-arachnoidal adhesions that bound the external surface of the tonsils to each other and to the cervical cord, thus forming the pocket. On the original film a fine trickle of Pantopaque could be plainly seen extending downward from the region of the obex from where apparently it dropped freely into the syrinx to come to rest opposite the tenth thoracic vertebra (compare with Fig. 5).

\section{TABLE I}

COMPARISON OF TOTAL PROTEIN CONTENT OF CEREBROSPINAL FLUID IN SYRINX AND LUMBAR FLUID

Protein Content of Cerebrospinal Fluid (mg./100 ml.)

Syrinx

Lumbar

$\begin{array}{llllllllll}16 & 17 & 23 & 23 & 23 & 29 & 29 & 33 & 33 & 42\end{array}$

$\begin{array}{llllllll}41 & 50 & 30 & 32 & 35 & 41 & 75 & 90\end{array}$

$\begin{array}{llllllllll}33 & 19 & 45 & 45 & 41 & 41 & 41 & 41 & 41 & 59\end{array}$ $\begin{array}{llllllll}41 & 50 & 15 & 30 & 20 & 38 & 35 & 33\end{array}$

cases in which this was accomplished, the fluid appeared to be normal cerebrospinal fluid. In 18 of these cases the protein content of the syrinx fluid was compared with that of the lumbar fluid. Protein ranged from 16 to $90 \mathrm{mg}$. per $100 \mathrm{ml}$. and that of the corresponding lumbar fluid ranged from 15 to $59 \mathrm{mg}$. per $100 \mathrm{ml}$. (Table 1). In 10 cases the protein content of the syrinx fluid was lower than that of the corresponding lumbar fluid and thus resembled ventricular fluid more closely than did the lumbar fluid. Contrariwise, in three cases of cystic tumours of the cervical cord with symptoms suggesting syringomyelia, the fluid was thick and yellow with a total protein content of $2,500,3,500$, and $5,000 \mathrm{mg}$. per $100 \mathrm{ml}$., respectively. It has been shown that fluid accumulating in cystic gliomas is the result of diffusion of plasma through the walls of the tumour capillaries (Gardner, Collis, and Lewis, 1963). It therefore represents interstitial (intercellular) fluid, whereas cerebrospinal fluid is transcellular in origin, which accounts for its low protein content. The interstitial fluid escaping from an ependymoma originating in the closed adult central canal may either redistend this canal or create a false passage that parallels it. Such tumours of the cervical cord may account for the fact that occasionally a patient with the clinical picture of syringomyelia will benefit by radiation therapy.

Of these 74 patients with syringomyelia, the incompetence of the foramen of Magendie was due to a Chiari malformation in 68, to a Dandy-Walker malformation in three, and to a congenital cyst obstructing the foramen of Magendie in three (Fig. 10). Such hindbrain malformations may account for some of the symptoms attributed to syringobulbia.

In all 68 cases of syringomyelia associated with the Chiari malformation, the cerebellar portion of the hernia was constituted by the tonsils rather than by the vermis as is usually the case with the severe infantile forms. The cerebellar tonsils were described as protruding 'into' the foramen magnum in five cases and 'through' it in 15 . The tonsils reached the level of the first cervical lamina in 29 cases, the second in 18, and the third in one. In 29 instances the herniated tonsils were cone-shaped and bound down to the medulla by a dense band of piarachnoid adhesions (Fig. 11). In 28 cases, the surgeon described a caudal dislocation of the obex, indicating a downward displacement of the medulla (Fig. 12A). In 36 cases the second cervical nerve roots pursued a cephalad course to their foramens of exit, indicating that this portion of the cervical cord was dislocated downward (Fig. 3; Fig. 12B). A posterior bulging of the medulla was described in 17 . In 24 cases the foramen of Magendie was enclosed by a membrane whose attachments indicated that it represented the unperforated rhombic roof. This membrane was lined by ependyma in two of the younger patients, and in one instance it contained choroid plexus. If these 24 cases are added to the three with Dandy-Walker malformation and to the three with cyst of the foramen of Magendie, there was a total of $\mathbf{3 0}$ cases in which a membrane entirely closed the foramen. As the membrane was incised, fluid spurted through it with each pulse beat. In addition there were eight cases in which a membrane partially enclosing the foramen was described. Such membranes surely cannot be considered merely incidental but a finding which would be anticipated if during embryonal life the rhombic roof were less permeable and correspondingly tougher than normal. At operation it 

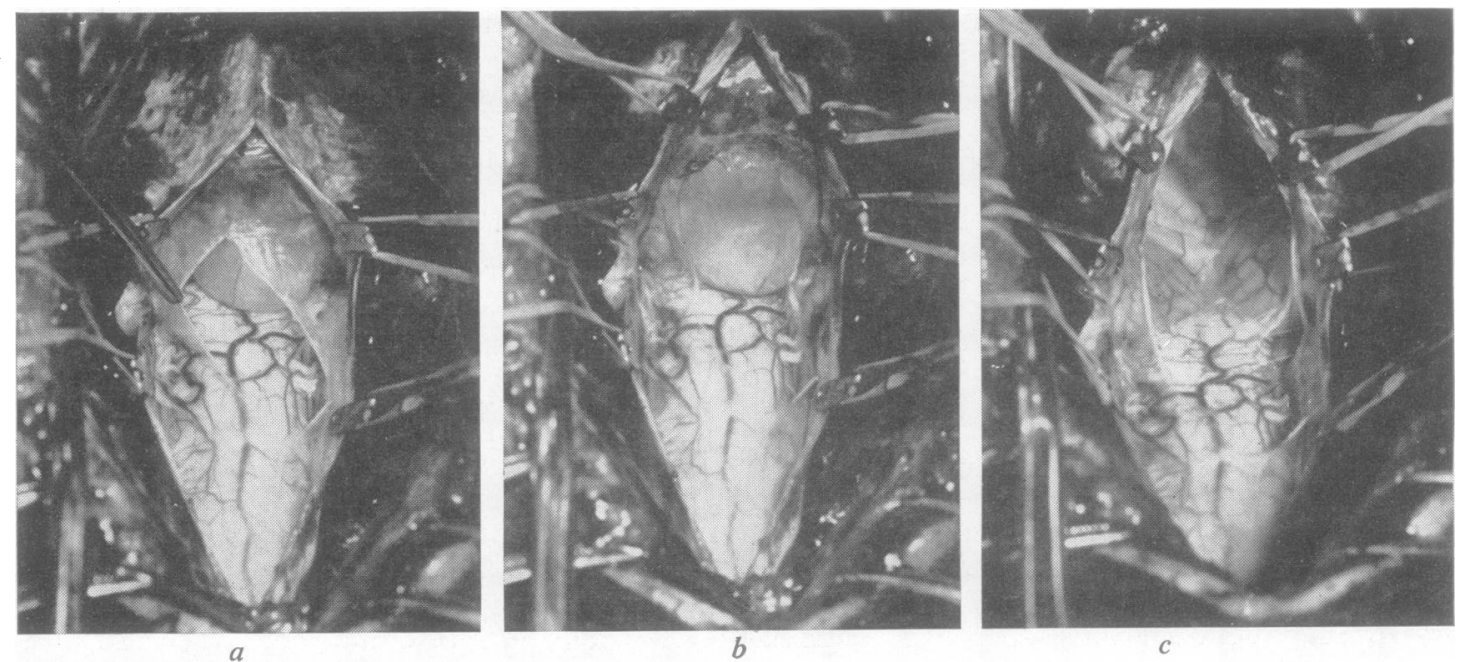

FIG. 10. Surgical exposure in a patient with syringomyelia.

a. A thin-walled cyst, entirely separate from the arachnoid, fills the cisterna magna. Its resemblance to the Dandy-Walker malformation is obvious in this view.

b. The cyst is blocking the foramen of Magendie. Although microscopically it resembled arachnoid, its position and attachments indicate that it represents an unperforated rhombic roof whose inner and outer layers became separated by an accumulation of ventricular fluid between them (Gardner et al., 1957). The contained fluid was clear and colourless with a total protein content of $29 \mathrm{mg}$. per $100 \mathrm{ml}$. Fluid with such a low protein content cannot be of pathological origin but mus $\stackrel{\mathbb{D}}{\mathrm{D}}$ come from the choroid plexus.

c. After evacuation the anterior wall of the cyst was found to have displaced the vermis upward and to have sealed the foramen of Magendie between the flattened tonsils.

is not feasible to examine the foramens of Luschka, but necropsy study in cases of imperforate foramen of Magendie (Gardner et al., 1957; Russell, 1949, cases 19 and 39) and of hydromyelia (Bézi, 1931) has disclosed similar membranes at the foramens of Luschka. In this more protected locus these membranes are apt to preserve the microscopic appearance of the rhombic roof, whereas at the foramen of Magendie the glial layer is usually missing and they resemble pia arachnoid.

The above figures do not indicate the true incidence of these features inasmuch as the operations were performed by several surgeons who, particularly in the early cases, undoubtedly overlooked some of them. For example, the lower medulla must have been dislocated caudally in all cases in which the upper cervical cord was so dislocated. The true incidence of unperforated rhombic roof undoubtedly was higher than the figures indicate, since this delicate membrane enclosing the foramen of Magendie may be readily torn by the surgeon's attempts to expose it. In some instances the tonsils were so adherent that the attempt to separate them had to be abandoned. In these cases the foramen of Magendie was not visualized and the fourth ventricle was opened by incising the vermis. In one early case in which it was stated that the cord was not cystic because it was not? fluctuant, the operative photograph (reproduced in Fig. 3) clearly shows a wide collapsed cord tha of before encephalography must have been distended with fluid. When the herniated tonsils were retracted in this case, a membrane was not disclosed and the surgeon therefore stated that the foramen of Magendie was patent. However, it is apparent that in this impacted hernia of the hindbrain the foramen, though patent, could not have been competent to allow free passage of the ventricular fluid pulse wave.

\section{POST-OPERATIVE RESULTS}

Immediately following operation there was improvement in some of the symptoms of 52 patients, no change in 11, worsening of the pre-operative symptoms in six, and five patients did not survive the operation. Of the pre-operative symptoms, subjective numbness, dissociated sensory loss, and pain were most likely to be improved, although motor power, astereognosis, ataxia, and bulbar palsies also were benefited in some patients. In several instances bulbar or long-tract symptoms, non-existent before, were precipitated by the operation. This was attri- 


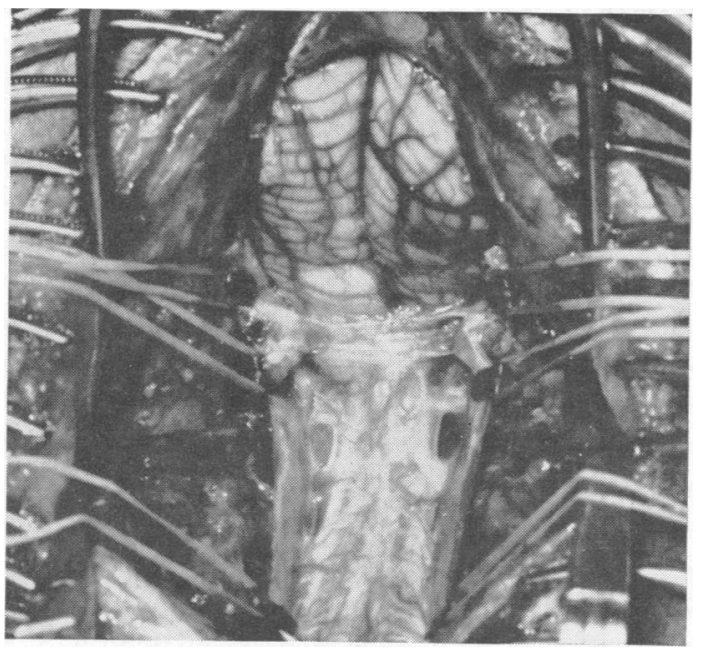

FIG. 11. Surgical exposure in syringomyelia. The coneshaped cerebellar tonsils are bound down by a band of thickened pia-arachnoid. The cystic cord has collapsed because of a pre-operative encephalogram.

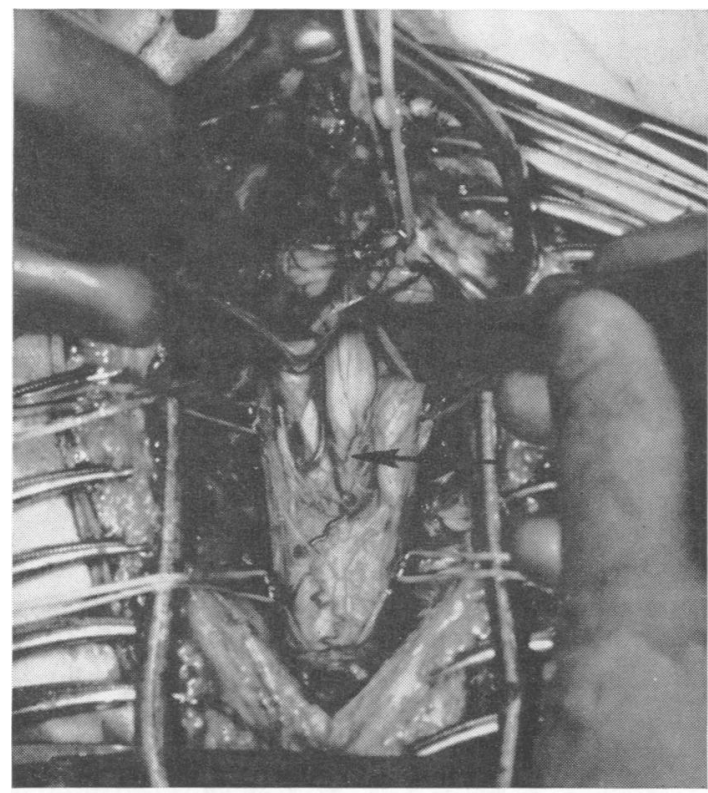

$a$

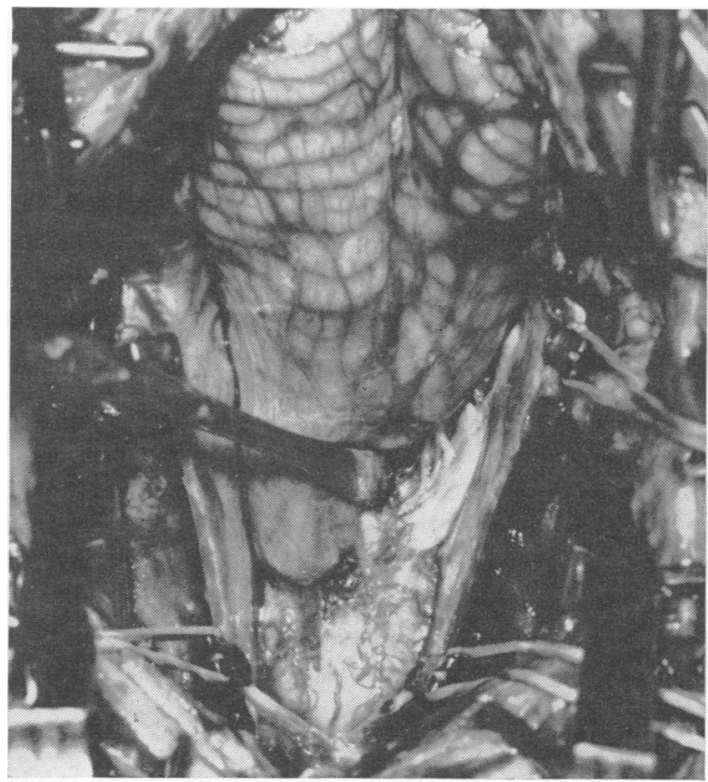

$b$

FIG. 12. Congenital hernias of the hindbrain in adults resembling those found in infants with myelocele.

a. Separation of the herniated tonsils discloses the fourth ventricle whose lower end (arrow) reaches the level of C2. Below the obex there may be seen the posterior buckling of the cervico-medullary junction. The vermis is displaced caudally almost to the level of the foramen magnum.

b. Exposure in a similar case demonstrating a pronounced upward course of the second cervical nerve root. In neither of these seyere herniations did the clinical picture indicate syringomyelia nor was a syrinx disclosed at operation. This suggests that in severe adult Chiari malformation, as is true in the infantile cases, the central canal may be squeezed shut at the level of the impaction. 
buted to oedema resulting from the sudden relief of the life-long compression of the medulla. In one patient, bulbar symptoms developed several days after operation, and necropsy disclosed a delayed intramedullary haemorrhage. In two patients the preoperative compensated hydrocephalus became uncompensated post-operatively to a degree that necessitated a ventriculo-jugular shunt. This was attributed to the entrance of blood and interstitial fluid into the subarachnoid space. Following discharge from the hospital one patient had two episodes of spontaneous subarachnoid haemorrhage from which he fortunately recovered. In three patients quadriparesis developed during operation. It was attributed to compression of the pyramidal decussation by a high odontoid process because of flexion of the head. (In one-third of the cases, radiographs disclosed the tip of the odontoid to be more than 10 $\mathrm{mm}$. above a line drawn from the posterior end of the hard palate to the base of the skull. This degree of basilar impression in syringomyelia is believed due to hydrocephalus unrecognized at birth and compensated in childhood.) This operation, therefore, entails a definite risk and should be reserved for those patients in whom total disability is threatened by progression of the symptoms.

Seventeen of these patients were operated upon before 1950 and thus provided an adequate followup. Of these 17 patients, one died of respiratory arrest 18 hours after operation. In two patients the symptoms were unchanged by the operation, and in three the symptoms were worse. In eight patients, or one-half the survivors of this group, the symptoms were improved when the patients were seen after intervals of $23,17,16,15,14$, nine, seven, and six years, respectively. The symptoms in the remaining three patients, seen 24,13 , and six years after operation, had been improved for five years, seven months, and one year, respectively, and then recurred.

\section{MICROSCOPIC FINDINGS}

Post-mortem material from eight cases of syringomyelia was available for study. Fifty-six cross sections from varying levels of these spinal cords were found to have included the syrinx. In 24 the syrinx was adjacent to the anterior commissure. In each of these the wall was partly lined with ependyma, with no ependyma elsewhere. This finding is consistent with a distension of the central canal. In 31 sections the wall of the syrinx was naked of ependyma. In these a central canal was present in its normal position and separate from the syrinx. This finding is consistent with a false diverticulum arising from some portion of the central canal or from the floor of the fourth ventricle. In the remaining slide no ependyma was present either in the wall of the syrinx or elsewhere.

\section{CONCLUSIONS}

In acquired pathological states the terms early and mild as opposed to late and severe are virtually synonymous; in congenital malformations the opposite is true. In either case, effective investigation of a disease process begins with the study of mild forms and progresses to the more severe. This principle, followed quite unintentionally in the study of congenital malformations of the hindbrain, led to the conclusion that syringomyelia is the mild expression of an embryonic defect which in its severe form results in myelocele.

In syringomyelia as in myelocele one finds the neural tube distended and imperforate, thus representing postnatal persistence of the embryonic state. In the embryo the degree of distension of the neural tube is determined by the permeability of the rhombic roof, and permeability in turn depends upon attenuation. The end stage of this attenuation is perforation. Therefore, an imperforate rhombic $\dot{\omega}$ roof persisting into postnatal life is evidence of N delayed attenuation and impaired permeability of the structure in embryonic life.

In syringomyelia as in myelocele one encounters the Chiari or occasionally the Dandy-Walker mal formation. Both malformations can be explained byo a pathological degree of distension of the embryonic $\overrightarrow{0}$ neural tube, in which overdistension of the fores of brain competes with that of the hindbrain. Such overdistension (hydrocephalomyelia) tends to become compensated by the same mechanism as does the normal distension. If compensation occurs sufficiently early the infant may appear normal, but the imprisoned hydrodynamic stresses will eventuate in syringomyelia. In brief the cause of syringomyleia should be sought not in the spinal cord but in the hindbrain.

The anatomical evidence accumulated in this study suggests that myelocele is due not to failure of closure but rather to rupture of the neural tube resulting from a degree of overdistension too severe to permit of compensation. This mechanistic theory is not supported by the findings of the experimental pathologists who, on the other hand, have not explained how an unclosed neural tube can become overdistended.

\section{REFERENCES}

Barry, A., Patten, B. M., and Stewart, B. H. (1957). Possible factors in the development of the Arnold-Chiari malformation. $J$. Neurosurg., 14, 285-301.

Benda, C. E. (1952). Developmental Disorders of Mentation and Cerebral Palsies. Grune and Stratton, New York. 
Bering, E. A. Jr. (1955). Choroid plexus and arterial pulsation of cerebrospinal fluid; demonstration of the choroid plexuses as a cerebrospinal fluid pump. Arch. Neurol. Psychiat. (Chic.), 73, 165-172.

(1962). Circulation of the cerebrospinal fluid. Demonstration of the choroid plexuses as the generator of the force for flow of fluid and ventricular enlargement. J. Neurosurg., 19, 405-413.

Bézi, I. (1931). Assimilation of atlas and compression of medulla. Arch. Path., 12, 333-357.

Cameron, A. H. (1957). The Arnold-Chiari and other neuro-anatomical malformations associated with spinal bifida. J. Path. Bact., 73, $195-211$.

Chiari, H. (1891). Uber Veränderungen des Kleinhirns infolge von Hydrocephalie des Grosshirns. Dtsch. med. Wschr., 17, 1172-1175.

- (1895). Ueber die Veränderungen des Kleinhirns des Pons und der Medulla oblongata in Folge von congenitaler Hydrocephalie des Grosshirns. Denkschr. Akad. Wissensch. Wiern. Mathnaturw. Kl., 63, 71-116.

Dandy, W. E. (1921). The diagnosis and treatment of hydrocephalus due to occlusions of the foramina of Magendie and Luschka. Surg. Gynec. Obstet., 32, 112-124.

Daniel, P. M., and Strich, S. J. (1958). Some observations on the congenital deformity of the central nervous system known as the Arnold-Chiari malformation. J. Neuropath. exp. Neurol., 17, 255-266.

Gardner, W. J. (1959a). Anatomic anomalies common to myelomeningocele of infancy and syringomyelia of adulthood suggest a common origin. Cleveland Clin. Quart., 26, 118-133.

- (1959b). Anatomic features common to the Arnold-Chiari and the Dandy-Walker malformations suggest a common origin. Ibid., 26, 206-222.

(1961). Rupture of the neural tube: the cause of myelomeningocele. Arch. Neurol. (Chic.), 4, 1-7.

(1964). Diastematomyelia and Klippel-Feil syndrome; relationship to hydrocephalus, syringomyelia, meningocele, meningomyelocele, and iniencephalus. Cleveland Clin. Quart., 31 19-44.
- , Abdullah, A. F., and McCormack, L. J. (1957). The varying expressions of embryonal atresia of fourth ventricle in adults. Arnold-Chiari malformation, Dandy-Walker syndrome, 'arachnoid' cyst of cerebellum, and syringomyelia. J. Neurosurg., 14, 591-607.

_, Collis, J. S. Jr., and Lewis, L. A. (1963). Cystic brain tumours and the blood-brain barrier. Arch. Neurol. (Chic.), 8, 291-298.

- McCormack, L. J., and Dohn, D. F. (1960). Embryonal atresia of the fourth ventricle. The cause of 'arachnoid cyst' of cerebellopontine angle. J. Neurosurg., 17, 226-237.

—, and Nosik, W. A. (1942). Experiences with encephalography in cerebellar tumor. Amer. J. Roentgenol., 47, 691-698.

- Spitler, D. K., and Whitten, C. (1954). Increased intracranial pressure caused by increased protein content in the cerebrospinal fluid; an explanation of papilledema in certain cases of small intracranial and intraspinal tumors, and in the GuillainBarré syndrome. New Engl. J. Med., 250, 932-936.

Greenfield, J. G., Blackwood, W., McMenemey, W. H., Meyer, A., and Norman, R. M. (1958). Neuropathology. Arnold, London.

Greenwald, C. M., Eugenio, M., Hughes, C. R., and Gardner, W. J. (1958). The importance of the air shadow of cisterna magna in encephalographic diagnosis. Radiology, 71, 695-701.

Leyden, E. (1876). Ueber Hydromyelus und Syringomyelie. Virchows Arch. path. Anat., 68, 1-26.

McLaurin, R. L., Bailey, O. T., Schurr, P. H., and Ingraham, F. D. (1954). Myeolomalacia and multiple cavitations of spinal cord secondary to adhesive arachnoiditis; experimental study. Arch. Path., 57, 138-146.

Padget, D. H. (1957). The Development of the cranial venous system in man, from the viewpoint of comparative anatomy. Contr. Embryol. Carneg. Instn, 36, 79-140.

Russell, D. S. (1949). Observations on the pathology of hydrocephalus. Spec. Rep. Ser. med. Res. Coun. (Lond.), no. 265.

Weed, L. H. (1917). The development of the cerebro-spinal spaces in pig and in man. Contr. Embryol. Carneg. Instn, 5, 1-116. 